\title{
Use of Nutritional Supplements in Amateur Tennis Players
}

\author{
Antonio Jesús Sánchez-Oliver ${ }^{1,2 *}$, Fernando Mata-Ordoñez ${ }^{3}$, Raúl Domínguez ${ }^{4,5}$ and Álvaro \\ López-Samanes ${ }^{6}$
}

1 Faculty of Sports Sciences, University Pablo Olavide, Spain; asanchez@upo.es

2 Faculty of Educational Sciences, University of Seville, Spain; asanchez38@us.es

3 NutriScience España, Córdoba, Spain; fmataor@gmail.com

4 College of Health Sciences, Alfonso X El Sabio University, Spain; rdomiher@uax.es

5 College of Health Sciences, Isabel I University, Spain;

6 School of Health Sciences, Francisco de Vitoria, Spain; alvaro.lopez@ufv.es

* Correspondence: asanchez@upo.es; Tel.: +34-656-305-480

\begin{abstract}
Literature on the use of nutritional supplements (NS) in tennis players is scarce. The objective of the present study was to evaluate NS consumption in a group of men's tennis players who participated in the 2016 Andalusian team championship. A total of 70 questionnaires from 7 different clubs were registered. The questionnaire was previously designed and evaluated through piloting in which the validity of the content, its application, its structure and its presentation were observed. The results showed that $100 \%$ of the sample group was in favor of NS consumption within the law, $88.6 \%$ claimed to have consumed them at some time and $61.4 \%$ presently consume them. The NS most consumed by study participants were sports drinks $(69.35 \%)$, energy bars (29\%), a vitamin complex (19.35\%), protein (serum) $(17.74 \%)$ and creatine (14.51\%). A high percentage of NS consumers thought that they had obtained positive results from NS consumption. The percentages and the findings regarding NS consumption in the present study were similar to the contributions made by other studies which evaluated supplementation in athletes, although with some subtle differences.
\end{abstract}

Keywords: nutritional supplements; tennis; ergogenic aids; amateurs

\section{Introduction}

An athlete's performance and state of health are closely linked to adequate nutrition [1], in addition to having great relevance in the prevention of, and recovery from, injuries [2].

A tennis player must combine high levels of muscle strength and power, speed and agility, coordination and decision making in conditions of fatigue and mental stress for long periods of time $[3,4]$ since a tennis match usually lasts an average of 90 minutes, and can last up to 4 or 5 hours [1]. In addition, a point in tennis has an average duration of 7 to 10 seconds, with recovery periods of between 10 and 90 seconds; depending on whether or not there is a court change-over [5].

Providing an adequate diet which helps to control performance limiting factors, facilitates a good recovery after training and matches, and helps to create better physiological adaptations for the tennis player's performance is of vital importance.

When the performance level increases considerably, adequate intake of energy and nutrients becomes even more critical as any small benefit acquired can provide an advantage during the competition. The possibility of improving performance often encourages athletes to consider nutritional supplements (NS) consumption. NS destined for athletes are becoming increasingly important and their consumption has been growing exponentially in recent years [6]. There are many NS on the market and their numbers also continue to grow vertiginously. Some NS are presented as solid foods, others as drinks and still others in concentrated and dosed forms [7]. Although NS use is 
widespread in the world of sports, only a few NS (e.g., creatine, sodium bicarbonate, caffeine) have been shown to result in improved sports performance [8].

Along these lines, the Australian Institute of Sport (AIS) has developed a classification system for sports NS in which the supplements are grouped into four categories according to their safety, legality and effectiveness [9]. This classification system for sports supplements is based on a riskbenefit analysis for each product which is performed by a group of medicine and sports nutrition experts [10].

NS consumption by amateur or professional athletes has continued to increase in recent years [11]. The prevalence of NS use among athletes has been estimated between $37 \%$ and $89 \%$ at the international level, with NS use more frequent in elite and older athletes [12]. In Spain, NS consumption is around 56\% [13], which is similar to consumption levels in countries like Norway (54\%) [14], but much lower than in countries such as Finland (73\%) [15], the United States (75\%) [16], or Sri Lanka (94\%) [17]. The increased consumption of these substances in sports has led to the emergence of different research aimed at estimating overall consumption of the same.

Although there are two reviews which talk about nutritional supplements in tennis, one by Ranchordas et al. (2013) [18] and the other by López-Samanes et al. (2015) [19], as well as a recent article on NS consumption in professional tennis players [20], there is very little literature which assesses NS consumption in amateur tennis players. The objective of the present study was to evaluate NS consumption in a group of amateur tennis players who participated in the men's category at the 2016 Andalusian team championship.

\section{Materials and Methods}

A non-experimental, cross-sectional and descriptive design was used. For this study, the selfreporting technique was used through an online questionnaire. Of the 72 questionnaires received, a total of 70 questionnaires from 7 different tennis clubs were successfully completed for players in the men's category who participated in the 2016 Andalusian team championship. The sample size met the minimum requirements for a $95 \%$ confidence with a margin of error of $5 \%$ [21]. The sampling pattern was random so as to adapt to the diversity of tennis players who participated in the 2016 Andalusian team championship as much as possible.

The questionnaire used in the study, which provided information about NS consumption, was previously validated by Sánchez-Oliver (2013), and achieve a 54\% of methodological quality in a review performed by Knapik et al. (2016) in which only 57 of the 164 different questionnaires they reviewed for the study of NS consumption received their approval [22]. The questionnaire was composed of three different sections: the first of which collected the social, personal and anthropometric data of the subjects; the second, which focused on sports activity practices and their contextualization; and the third, which gathered information about diet and nutritional supplementation. The questionnaires were answered anonymously and with prior informed consent from each participant.

For statistical treatment of the data, the SPSS Statistical Package was used (Statistical Package for Social Sciences, version 23.0) (SPSS Inc., Chicago, IL). The descriptive study was performed through the calculation of frequency tables for the categorical variables and measures of position and dispersion for the qualitative variables.

\section{Results}

Table 1 shows the age, height, weight and body fat data of the sample group. Data pertaining to the practice of sports: years with a federation license, the number of weekly training sessions and the time devoted to each training session are listed in Table 2.

Table 1. Age, Height, Weight and Body Fat 


\begin{tabular}{lcc}
\hline Age (years) & 21.8 & \pm 3.1 \\
Height (m) & 177.8 & \pm 3.9 \\
Weight (kg) & 72.1 & \pm 4.2 \\
Body Fat (\%) & 13.6 & \pm 2.1 \\
\hline M= mean. SD=standard deviation
\end{tabular}

Seventy percent $(n=49)$ of the participants followed some type of diet, defined as any nutrition and nutritional control with a grounded structure. The Mediterranean diet $(n=20)$ and the low-fat diet $(n=16)$ were most frequently chosen by participants in the study.

Table 2. Participant Characteristics

\begin{tabular}{rcc} 
& \multicolumn{2}{c}{ Total $(\mathrm{n}=70)$} \\
\hline & $\mathbf{M}$ & DS \\
\hline Years federated & 10.7 & \pm 3.1 \\
Weekly training sessions & 4.2 & \pm 0.7 \\
Hours of training per week & 1.45 & \pm 0.25 \\
\hline
\end{tabular}

$\mathrm{M}=$ mean; $\mathrm{SD}=$ standard deviation

Of the sample group, $95.7 \%(\mathrm{n}=67)$ were in favor of NS consumption within the law, $88.6 \%$ (n $=62)$ reported having consumed them at some time and $61.4 \%(n=43)$ continue to consume them. Improving sports performance $(87.1 \%, \mathrm{n}=54)$ and alleviating some dietary deficit $(46.8 \%, \mathrm{n}=29)$ were the most frequent justifications for NS consumption. Table 3 shows the NS most consumed by study participants were sports drinks (69.35\%), energy bars $(29 \%)$, a vitamin complex $(19.35 \%)$, protein (serum) $(17.74 \%)$ and creatine $(14.51 \%)$.

Table 3: Nutritional Supplements Consumption

\begin{tabular}{lcc} 
& \multicolumn{2}{c}{ Total $(\mathrm{n}=70)$} \\
\hline Sports Drinks & \% & N \\
Energy Drinks & 29.35 & 43 \\
Vitamin Complex & 19.35 & 12 \\
Protein (serum) & 17.74 & 11 \\
Creatine & 14.51 & 9 \\
Carbohydrates & 11.29 & 7 \\
Protein (non-serum) & 11.29 & 7 \\
\hline
\end{tabular}

The places where subjects went most to buy NS were specialized stores $(32.25 \%)$ and the internet (29\%). Trainers $(27.42 \%)$ and teammates $(19.35 \%)$ were the most influential on study participants regarding NS consumption.

Of the sample group, the $61.3 \%$ of subjects who consumed NS thought that they obtained positive results after NS use. Although $1.61 \%$ of the subjects had consumed, or would consume, a NS which would increase performance even though it were harmful to their health, none of the subjects had consumed, nor would they consume, any type of illegal or prohibited NS. When asked to rate the use of supplements or substances which are harmful or prohibited in amateur tennis on a scale 
from 1 to $5,87.1 \%$ of the respondents rated the use of said supplements and substances as a "2" and the remaining respondents $(12.9 \%)$ rated their use as a " 1 " (minimum).

\section{Discussion}

Nutrition and training are determining factors in the overall performance of tennis players [23]. However, it is likely that, for various reasons, not all athletes can consume a diet which meets their nutritional needs. Consequently, NS are considered to be additional support for regular nutrition. In addition, when the competition level increases considerably, adequate intake of energy and nutrients becomes even more critical and any small benefit acquired can provide an advantage during competition. The possibility of improving performance often encourages athletes to consider NS consumption. NS destined for athletes are becoming increasingly more important and their consumption has been growing exponentially in recent years [24]. Obtaining accurate data on the prevalence of NS use has limitations; studies suggest that nutritional supplement (NS) consumption ranges from 37 to $89 \%$ and varies greatly depending on the context [12]. In this regard, the percentage of NS consumption reported in this study (88.6\%) was within this margin, although close to the upper limit. However, these data were above the consumption rate reported by amateur athletes from other intermittent sports such as basketball (71.2\%) [25]. When comparing the data obtained in this study with those from the two studies found pertaining to NS consumption in tennis players $(80-100 \%)$, we could verify that the data were within that range, although with the notable difference that the other two studies focused on professional and high-level tennis players [1, 20], not amateurs.

The reason for NS consumption varies greatly depends on the specific characteristics of each sport and the specific situation of the athlete [7]. The most frequently reported reasons to justify NS consumption by participants were, to improve their athletic performance $(87.1 \%)$ and to alleviate some dietary deficit $(46.8 \%)$. Although not necessarily in the same order of priority, similar results had been found in other studies in which improving sports performance [20,25-27] and mitigating some dietary deficits $[20,25,28]$ were some of the most frequently reported justifications for NS consumption by athletes.

According to different recent studies reviewed which evaluated NS consumption in several sports, the most popular NS for amateur sports are usually sports drinks, vitamins and minerals, caffeine, creatine and protein supplements [25, 29-32]. With the exception of the energy bars (29\%), the data coincided with those recorded in our study. If we compare these findings with the ones from the only study which collected data regarding which NS are consumed in tennis, we can verify that sports drinks, protein supplements, vitamin and mineral complexes, and creatine coincide among the most frequently chosen [20].

As in some of the studies reviewed $[13,25,28]$, specialized stores were the places where the subjects most frequently went to buy their NS. As recent studies have shown [25, 33], the internet is an emerging market which is gaining more and more strength in the sale of NS for athletes; therefore, regulating NS sales over the internet is necessary in order to ensure the safety and legality of the same [10].

NS management practices are often guided by family, friends, teammates, trainers, the internet or salespeople, rather than dieticians-nutritionists, sports doctors or other sports science professionals [34]. The data obtained in this study were similar to those found in the scientific literature reviewed, where family or friends, coaches and teammates were the ones who most frequently recommended using NS to athletes $[25,35,36]$. The only study found which had gathered data regarding who recommends NS consumption in tennis players was López-Samanes et al, 2017, where physical trainers $(50.7 \%)$, coaches $(39.1 \%)$, on the one hand, and sports nutritionists $(62.5 \%)$, on the other, most frequently recommended their use. These data partially agree with the data reported in this study, where coaches $(27.4 \%)$ were the ones who most frequently recommended using NS.

In this study, $61.3 \%$ of the subjects thought that they had obtained positive results after NS consumption. Nevertheless, the other studies reviewed show disparity in this respect; the percentage of study subjects perceiving positive results after NS consumption were higher in some studies (74.7- 
$82.4 \%)[13,25,37]$, yet much lower in others (55\%) [38] with respect to the results obtained in our study.

Although $95.7 \%$ of the subjects were in favor of NS consumption, a positive fact which should be noted is that $98.4 \%$ of them were against the consumption of substances which are harmful to health, despite increasing performance, and $100 \%$ of the subjects reported that they had never consumed, nor would they consume, an illegal or prohibited substance. In addition, most thought that the use of supplements or substances which are harmful or prohibited is low in amateur tennis.

There are numerous studies in which NS users were not aware of what they were taking; sometimes consuming supplements which were harmful to their health and/or which contained illegal or prohibited added substances [39-41]. In addition, research shows that many people do not receive professional information about nutritional supplements [41-43]. Therefore, it is important to inform athletes about the types of supplements, their properties and risks, accounting for their use with regard to diet.

Under normal conditions, when athletes consume a diet balanced for their needs, most meet their energy and nutritional requirements. NS use should complement a well-chosen nutrition plan, as it is rarely effective outside of these conditions and is not justified in the case of young athletes who may have significant gains in performance through maturation in age, sports experience or the development of a sports nutrition plan. The need for NS becomes essential in cases of inadequate diets, but in a limited and appropriate way [31].

Standardization and categorization of NS are essential for regulating them. From policies applied to sports nutrition, it is recommended that NS-related legislation should be a specific section, making it possible to know the advantages and limitations of, and evidence for, NS use in the sports population [10].

Although the subjects were aware of the use of banned or harmful substances, informing them about the risks associated with NS use, how to use them effectively and, perhaps more importantly, how to maximize the intake of nutrients from food in order to minimize or suppress NS use may be the educational areas most in need of improvement. In addition, regulating the production, labeling, information and publicity of NS should be one of the measures taken from within the legislative framework.

\section{Conclusions}

Of the federated amateur tennis players in the Andalusian men's category who were surveyed, $89 \%$ had used a NS at some time. Sports drinks, energy bars, a vitamin complex, proteins and creatine were the NS most frequently consumed by these tennis players. Improving sports performance and alleviating some dietary deficit were the most frequently given reasons to justify NS consumption in amateur tennis players. Although almost the all of the subjects were in favor of NS consumption, they were against the use of prohibited or harmful substances.

\section{Limitations and Suggestions for Future Research:}

A study based on the analysis of self-reports always offers some important limitations since some questions are left to the interpretation and perception of the subjects who complete them. The lack of questions about frequency of use and consumption, as well the fact that the study did not contemplate the training and/or competition phase during which NS were ingested are its biggest limitations. Both of these issues should be addressed in subsequent studies. Likewise, it would be interesting if future research included a more detailed analysis of NS consumption, including quantity, frequency, time and method of consumption, etc. Additionally, it would be very useful to examine the eating habits of tennis players in order to allow for a better discussion and more definitive conclusions.

\section{Author Contributions:}


A.J.S.O. and F.M.O. equally contributed to study design and data collection. R.D. contributed to data analysis, and writing the manuscript. Editing of the manuscript was done by A.L.S. and A.J.S.O.

\section{Conflicts of Interest:}

There is no financial or personal conflict of interest to declare.

\section{References}

1. M. Kondric, D. Sekulic, O. Uljevic, G. Gabrilo, and M. Zvan, "Sport nutrition and doping in tennis: an analysis of athletes' attitudes and knowledge.," J. Sports Sci. Med., vol. 12, no. 2, pp. 290-7, 2013.

2. D. S. Moran et al., "Dietary intake and stress fractures among elite male combat recruits," J. Int. Soc. Sports Nutr., vol. 9, no. 1, p. 6, 2012.

3. M. A. Christmass, S. E. Richmond, N. T. Cable, P. G. Arthur, and P. E. Hartmann, “Exercise intensity and metabolic response in singles tennis," J. Sports Sci., vol. 16, no. 8, pp. 739-747, Jan. 1998.

4. M. Iacoboni, "Playing tennis with the cerebellum.," Nat. Neurosci., vol. 4, no. 6, pp. 555-556, Jun. 2001.

5. P. O'Donoghue and B. Ingram, "A notational analysis of elite tennis strategy," J. Sports Sci., vol. 19, no. 2, pp. 107-115, Jan. 2001.

6. J. Gahche et al., "Dietary supplement use among U.S. adults has increased since NHANES III (19881994).," NCHS Data Brief, no. 61, pp. 1-8, 2011.

7. N. Palacios et al., "Ayudas ergogénicas nutricionales para personas que realizan ejercicio físico," Arch. Med. del Deport., vol. XXIX, no. Suplemento 1, pp. 5-80, 2013.

8. D. Bishop, "Dietary supplements and team-sport performance," Sports Medicine, vol. 40, no. 12. pp. 995-1017, 2010.

9. Australian Institute of Sport (AIS), "Supplements." [Online]. Available: https://www.ausport.gov.au/ais/sports_nutrition/supplements/classification. [Accessed: 11-Apr-2018].

10. A. J. Sánchez Oliver, Suplementación nutricional en la actividad físico-deportiva : análisis de la calidad del suplemento proteico consumido. Granada: Editorial de la Universidad de Granada, 2013.

11. L. Burke and V. Deakin, "Clinical Sports Nutrition, 4th Edition," in Clinical Sports Nutrition, 2010, p. 369.

12. D. T. Thomas, K. A. Erdman, and L. M. Burke, "American College of Sports Medicine Joint Position Statement. Nutrition and Athletic Performance," Med Sci Sport. Exerc, vol. 48, no. 3, pp. 543-568, 2016.

13. A. Sánchez-Oliver, M. Miranda-León, and E. Guerra-Hernández, "Estudio estadístico del consumo de suplementos nutricionales y dietéticos en gimnasios," Arch. Latinoam. Nutr., vol. 58, no. 3, pp. 221-227, 2008.

14. J. Sundgot-Borgen, B. Berglund, and M. K. Torstveit, "Nutritional supplements in Norwegian elite athletes - Impact of international ranking and advisors," Scand. J. Med. Sci. Sport., vol. 13, no. 2, pp. 138-144, 2003.

15. A. Heikkinen, A. Alaranta, I. Helenius, and T. Vasankari, "Dietary supplementation habits and perceptions of supplement use among elite Finnish athletes," Int. J. Sport Nutr. Exerc. Metab., vol. 21, no. 4, pp. 271-279, 2011.

16. D. M. Ahrendt, “Ergogenic aids: Counseling the athlete," Am. Fam. Physician, vol. 63, no. 5, pp. 913922, 2001.

17. A. De Silva, Y. Samarasinghe, D. Senanayake, and P. Lanerolle, "Dietary supplement intake in national-level Sri Lankan athletes," Int. J. Sport Nutr. Exerc. Metab., vol. 20, no. 1, pp. 15-20, 2010.

18. M. K. Ranchordas, D. Rogersion, A. Ruddock, S. C. Killer, and E. M. Winter, "Nutrition for tennis: practical recommendations.," J. Sports Sci. Med., vol. 12, no. 2, pp. 211-24, Jun. 2013.

19. A. Lopez-Samanes, J. F. Ortega Fonseca, V. E. Fernandez Elias, S. Borreani, J. L. Mate-Munõz, and M. S. Kovacs, "Nutritional ergogenic aids in Tennis: A brief review," Strength and Conditioning Journal, vol. 37, no. 3. pp. 1-11, 2015.

20. Á. López-Samanes, V. Moreno-Pérez, M. S. Kovacs, J. G. Pallarés, R. Mora-Rodríguez, and J. F. Ortega, "Use of nutritional supplements and ergogenic aids in professional tennis players," Nutr. Hosp., vol. 34, no. 6, p. p.1463-1468, 2017.

21. W. G. Cochran, “Sampling Techniques," Technometrics, vol. 20, no. 1. p. 104, 2007. 
22. J. J. Knapik, R. A. Steelman, S. S. Hoedebecke, K. G. Austin, E. K. Farina, and H. R. Lieberman, "Prevalence of Dietary Supplement Use by Athletes: Systematic Review and Meta-Analysis.," Sports Med., vol. 46, no. 1, pp. 103-23, Jan. 2016.

23. A. J. Sánchez-Oliver, F. Mata-Ordoñez, M. Grimaldi-Puyana, and R. Domínguez, "Necesidades nutricionales e hídricas en el tenis," ITF Coach. Sport Sci. Rev., vol. 73, no. 25, pp. 13-15, 2017.

24. R. L. Bailey et al., “Dietary Supplement Use in the United States, 2003-2006,” J. Nutr., vol. 141, no. 2, pp. 261-266, 2011.

25. A. J. Sánchez-Oliver and M. Grimaldi-Puyana, “Análisis del consumo de suplementos nutricionales en jugadores de la liga EBA," Cuad. Psicol. del Deport., vol. 17, no. 3, 2017.

26. J. A. Parnell, K. Wiens, and K. A. Erdman, “Evaluation of congruence among dietary supplement use and motivation for supplementation in young, Canadian athletes," J. Int. Soc. Sports Nutr., vol. 12, no. 1, 2015.

27. K. Wiens, K. A. Erdman, M. Stadnyk, and J. A. Parnell, “Dietary supplement usage, motivation, and education in young Canadian athletes," Int. J. Sport Nutr. Exerc. Metab., vol. 24, no. 6, pp. 613-622, 2014.

28. K. A. Erdman, T. S. Fung, and R. A. Reimer, "Influence of performance level on dietary supplementation in elite Canadian athletes," Med. Sci. Sports Exerc., vol. 38, no. 2, pp. 349-356, 2006.

29. J. J. Knapik, R. A. Steelman, S. S. Hoedebecke, K. G. Austin, E. K. Farina, and H. R. Lieberman, “Prevalence of Dietary Supplement Use by Athletes: Systematic Review and Meta-Analysis," Sport. Med., vol. 46, no. 1, pp. 103-123, 2016.

30. R. American Dietetic Association, D. M. Dietitians of Canada, L. American College of Sports Medicine, N. R. Rodriguez, N. M. Di Marco, and S. Langley, “American College of Sports Medicine position stand. Nutrition and athletic performance.," Med. Sci. Sports Exerc., vol. 41, no. 3, pp. 709-31, Mar. 2009.

31. D. T. Thomas, K. A. Erdman, and L. M. Burke, "Position of the Academy of Nutrition and Dietetics, Dietitians of Canada, and the American College of Sports Medicine: Nutrition and Athletic Performance," 2016.

32. R. J. Maughan, F. Depiesse, and H. Geyer, "The use of dietary supplements by athletes," in Journal of Sports Sciences, 2007, vol. 25, no. SUPPL. 1, pp. 103-113.

33. A. J. Sánchez-Oliver, J. Fernández-Gavira, M. Grimaldi-Puyana, and J. García-Fernández, "Consumo de suplementos nutricionales y sustancias nocivas en culturismo: implicaciones para su gestión," Rev. Psicol. del Deport., vol. 27, no. 3, pp. 76-81, 2018.

34. H. Braun, K. Koehler, H. Geyer, J. Kleinert, J. Mester, and W. Schänzer, “Dietary supplement use among elite young German athletes," Int. J. Sport Nutr. Exerc. Metab., vol. 19, no. 1, pp. 97-109, 2009.

35. K. Froiland, W. Koszewski, J. Hingst, and L. Kopecky, “Nutritional supplement use among college athletes and their sources of information," Int J Sport Nutr Exerc Metab, vol. 14, no. 1, pp. 104-120, 2004.

36. G. Slater, B. Tan, and K. C. Teh, “Dietary supplementation practices of Singaporean athletes," Int. J. Sport Nutr. Exerc. Metab., vol. 13, no. 3, pp. 320-332, 2003.

37. A. Sánchez Oliver, M. T. Miranda León, and E. Guerra-Hernández, "Estudio estadístico del consumo de suplementos proteícos en gimnasios," Nutr. Hosp., 2011.

38. J. L. Goston and M. I. Toulson Davisson Correia, "Intake of nutritional supplements among people exercising in gyms and influencing factors," Nutrition, vol. 26, no. 6, pp. 604-611, 2010.

39. S. R. Bird, C. Goebel, L. M. Burke, and R. F. Greaves, "Doping in sport and exercise: anabolic, ergogenic, health and clinical issues," Annals of Clinical Biochemistry, vol. 53, no. 2. pp. 196-221, 2016.

40. O. de Hon, H. Kuipers, and M. van Bottenburg, "Prevalence of Doping Use in Elite Sports: A Review of Numbers and Methods," Sports Medicine, vol. 45, no. 1. pp. 57-69, 2014.

41. J. M. Martínez-Sanz, I. Sospedra, C. M. Ortiz, E. Baladía, A. Gil-Izquierdo, and R. Ortiz-Moncada, "Intended or unintended doping? A review of the presence of doping substances in dietary supplements used in sports," Nutrients, vol. 9, no. 10. 2017.

42. D. M. Schaffer, N. P. Gordon, C. D. Jensen, and A. L. Avins, "Nonvitamin, nonmineral supplement use over a 12-month period by adult members of a large health maintenance organization," J. Am. Diet. Assoc., vol. 103, no. 11, pp. 1500-1505, 2003.

43. H. H. Tsai, H. W. Lin, A. Simon Pickard, H. Y. Tsai, and G. B. Mahady, "Evaluation of documented drug interactions and contraindications associated with herbs and dietary supplements: A systematic literature review," International Journal of Clinical Practice, vol. 66, no. 11. pp. 1056-1078, 2012. 